\title{
DELIVERING NATIONAL ECONOMIC INFRASTRUCTURE IN SOUTH AFRICA: A REVIEW OF STRATEGIC INTEGRATED PROJECT \#3
}

\author{
DEENA GOVENDER \\ Trans-Caledon Tunnel Authority, South Africa
}

\begin{abstract}
The South African (SA) government has for many years pursued much needed social and economic transformation. This journey is far from a path void of obstacles and complicated challenges. However, the significance of providing economic and social infrastructure is one of the strategies prioritised by government to enable entrepreneurship, employment opportunities, access to essential services by the poor, and empower people through education and skills development. In this regard, to address critical socio-economic challenges in SA, in 2012, the Government adopted a National Infrastructure Plan (NIP) supportive of the SA National Development Plan (NDP) imperatives. The vision of the NIP is to transform the economic landscape through the implementation of strategically integrated infrastructure projects. The NIP strategy foresaw economic sustainability for the future and an improved standard of living for many impoverished communities in SA. In this light, and in support of the NIP vision, the Presidential Infrastructure Coordinating Commission (PICC) was established to integrate and coordinate the original eighteen Strategic Integrated Projects (SIPs). SIP projects were selected based on their catalytic nature and grouped into several infrastructure programs (SIP-1 to SIP-18). In January of 2013, the Minister of Water and Environmental Affairs formally directed the Trans-Caledon Tunnel Authority (TCTA) to take-up the program coordination role for SIP-3. This study is to better understand the SIP-3 Coordination function and performance through a review of the SIP-3 program. The paper highlights a path through SIP-3 Coordination experiences from its inception in 2012 to present (2021). The review is in line with, but not limited to, the SIP-3 program business plan, the coordination function of SIPs, the intended and realised impact of the program. Lessons are drawn from the review outcomes and recommendations are made for improving national infrastructure development and coordination that is supportive of economic and social advancement in South Africa.
\end{abstract}

Keywords: South Africa, infrastructure, planning, strategies, social, economic, sustainable.

\section{INTRODUCTION}

As detailed in the National Development Plan (NDP), South Africa needs a strong network of economic infrastructure designed to support the country's medium and long-term economic and social objectives [1]. In response to critical economic challenges in South Africa, in February 2012 during the State of the Nation Address, the President announced the adoption of the National Infrastructure Plan (NIP) [2], that comprises of strategic projects which support the National Development Plan (NDP) imperatives. It is noteworthy to mention that the United Nations 2030 Agenda [3] for sustainable development reflects on South Africa's vision through its NDP 2030. The goal of the NIP is to transform the economic landscape and to create significant employment opportunities through structured planning and implementation of strategic projects across the country. By leveraging job creation, skills development and localisation through a long-term infrastructure pipeline is one of the ways intended for South Africans to collectively build an equitable society.

The NIP recognised that weak capacity, poor coordination, and weak integration limit the development impact of infrastructure. Accordingly, in response to these challenges, Cabinet resolved to establish the Presidential Infrastructure Coordinating Commission 
(PICC) to: coordinate, integrate and accelerate infrastructure implementation; monitor the NIP from a central standpoint; identify and assign responsibility and accountability of infrastructure implementation; develop a 20-year planning framework beyond one government administration to avoid an uninterrupted infrastructure roll-out.

As such, Government, through the PICC, established SIPs, and in April 2012, SIPs Programs (SIP-1 to SIP-18) had been launched across the country [4]. These projects were identified, developed, and approved with the intention of promoting and catalysing economic development, as well as addressing service delivery in SA's impoverished provinces.

The objective of this paper is to highlight South African national infrastructure development through its SIPs programs, with a focus on SIP-3. The paper seeks to inform and define the path traversed by SIP-3 in its coordination role and function within its governance framework and seeks to accentuate the SIP-3 program and coordination developments and challenges. The purpose of the paper is to: describe the SIP-3 program background and experiences; review the SIP-3 program, function, and impact reflective of its objectives; draw review lessons; make recommendations in improving the SIP-3 program function, and effectiveness. The resultant outcome of this paper is intended to guide an informed approach in the evolution of strategic integrated infrastructure development within South Africa.

\section{METHODOLOGY}

The research was conducted through the collection of data from the combination of a desktop qualitative review of literature on SIPs, a workshop, a seminar, and interviews which shadowed a thematic analysis approach. The literature review focused on the analysis of key sourced information which included industry and government publications on infrastructure development, as well as peer reviewed journal articles, technical reports, other publications on SIPs, and the SIP-3 Business Plan. The paper development benefited from a one-day workshop and a knowledge sharing seminar relating to the review of SIP-3 which focused on the accomplishments and challenges faced by the program. Each session was well attended by SIPs stakeholders comprising of built environment specialists, infrastructure finance specialists, engineers, and project managers. Participants in the workshop and seminar deliberated broadly on the SIPs programs, the associated challenges principally affecting SIP-3 and SIPs in general, as well as opportunities which exist in improving the effectiveness of the SIPs business.

The author's job responsibilities and knowledge of the NIP and SIPs progression also contributed to the research construct. Contextual information was extracted from several policies, including the following: The New Growth Path (NGP); the NDP; the NIP and the Infrastructure Development Act (IDA). Ultimately, the data collection included interviews with the SIP-3 program staff and stakeholders. Most insights into the SIP-3 Coordination function were gained from provincial social and economic development partners, previous SIPs coordinators, Project Owners, PICC SIPs leads and managers. The information was supplemented with SIP coordination memos, letters, meeting records and progress reports.

\section{UNPACKING THE SIP-3 PROGRAM (SOUTH-EASTERN NODE AND CORRIDOR DEVELOPMENT)}

At the onset of SIPs, the SIP-3 program comprised of 12 projects. These projects, for ease of coordination, were clustered into nine (see Table 1) theme-linked projects. 
Table 1: Original SIP-3 projects. (Source: SIP-3 Business Plan 2012.)

\begin{tabular}{|c|l|l|}
\hline Project & Project name & Project owner \\
\hline P1 & Manganese Sinter Plant & $\begin{array}{l}\text { Kalagadi Manganese and } \\
\text { Industrial Development } \\
\text { Corporation (IDC) }\end{array}$ \\
\hline P2 & Manganese Rail Upgrade & Transnet \\
\hline P3 & Manganese Smelter & IDC, Kalagadi Manganese \\
\hline P4 & Transhipment Hub & Transnet \\
\hline P5 & Mthombo Refinery & PetroSA \\
\hline P6 & N2 Wild Coast Highway & SANRAL \\
\hline P7 & $\begin{array}{l}\text { Clustered projects - Mthatha Airport, N2-Mthata } \\
\text { Bridge and the Nelson Mandela Legacy Bridge }\end{array}$ & $\begin{array}{l}\text { Eastern Cape Provincial } \\
\text { Government }\end{array}$ \\
\hline P8 & Power Transmission and Distribution & Eskom \\
\hline P9 & Mzimvubu Water Project & DWS \\
\hline
\end{tabular}

SIP-3 was among the first SIPs launched, with the TCTA being appointed in April 2012 to coordinate its implementation. In January 2013, the Minister of Water and Environmental Affairs formally directed the TCTA to take-up the program coordination role for the SIP-3 program. The program, referred to as the South-Eastern Node and Corridor Development, mainly focuses on the catalytic development of the Eastern Cape province of South Africa, and to a smaller degree the Northern Cape and Kwa-Zulu Natal provinces.

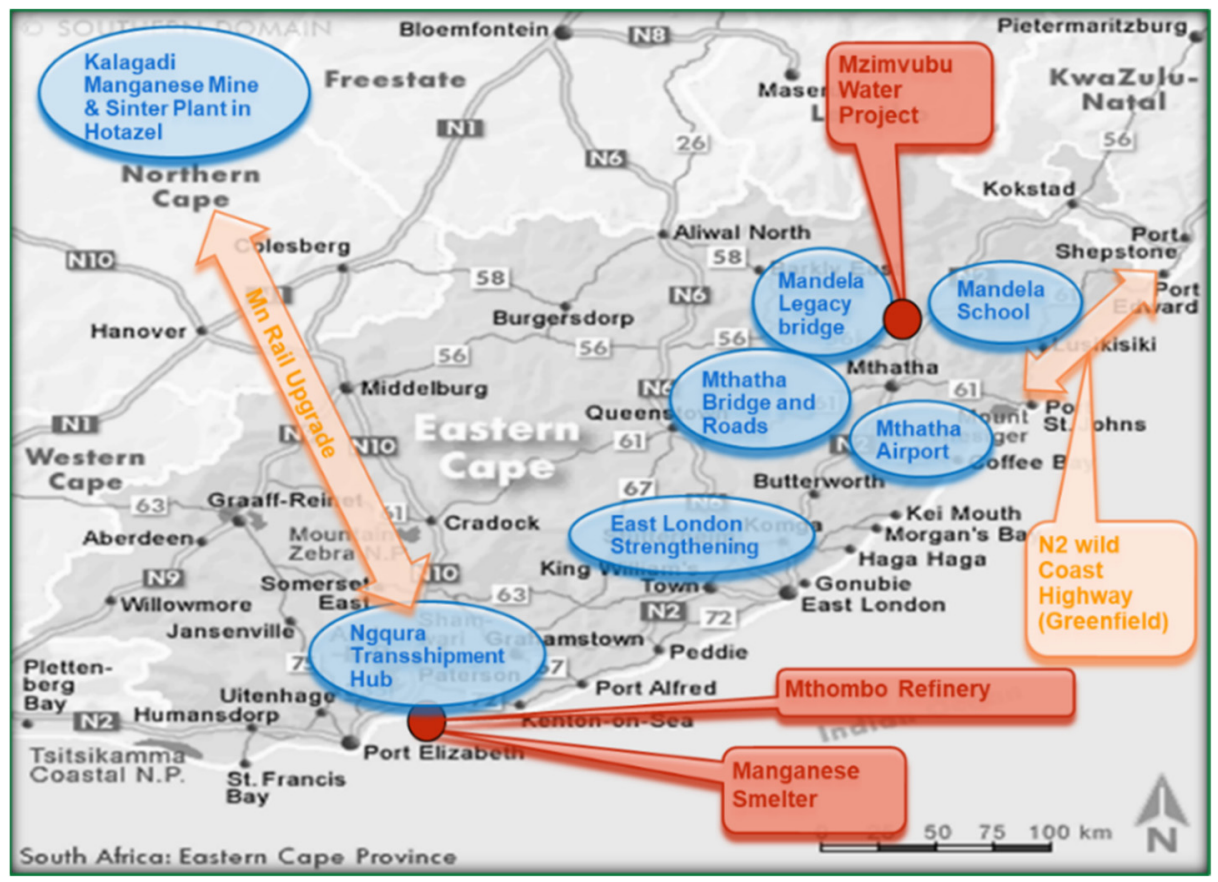

Figure 1: Map of the Eastern Cape province, depicting the location of key SIP-3 project sites. (Source: SIP-3 Progress Report.) 
Fig. 1 illustrates the location of SIP-3 projects within the Eastern Cape, Northern Cape, and the Kwa-Zulu Natal provinces. Tabs highlighted in blue are projects that have been completed. Tabs highlighted in orange represent projects that are in the construction phase but have experienced delays. Tabs highlight in red represent projects that are on hold or have not started due to challenges experienced, resulting in implementation delays.

Investments in infrastructure such as energy, water, transportation, and communication technologies promote economic growth and help to alleviate poverty and improve living conditions in developing countries [5]. Within this frame of understanding, the primary aim of SIP-3 is to unlock economic development in the Eastern Cape by supporting industrialisation, agriculture development, tourism, mining, and the automotive sector. More specifically, SIP-3 aims to achieve the following:

- Strengthen the economic development of the Port Elizabeth area through an upgraded manganese railway line from the Northern Cape, beneficiation of manganese by means of a new sinter plant at Hotazel and a new smelter plant, as well as a new manganese terminal, located at Coega;

- Unlock the industrial and export potential of the Eastern Cape region through the development of a multiple purpose transhipment hub at Ngqura, and the establishment of the proposed Mthombo oil refinery, also located in Coega;

- Promote rural development in the Eastern Cape through a new dam, irrigation and hydro-electric scheme on the Mzimvubu River, and enhance integration of the region with national supply chains through the N2-Wild Coast Highway and a number of smaller, transport-related projects;

- Enhance electrical transmission within the eastern part of the province, through the Greater East London Strengthening project.

The institutional arrangement for coordinating the SIP-3 program is reflected in Fig. 2. With respect to coordination and monitoring activities, the TCTA, as the SIP-3 Coordinator reports to the PICC, while actively inter-facing with the Inter-Governmental Forum (IGF) or as defined in the IDA, Act 23 of 2014, Forum of Executive Authorities (FEA) for regular guidance. All SIP-3 stakeholders and specialists formally convene on a quarterly basis constituting a Program Technical Committee (PTC), where technical inputs are disseminated and deliberated upon with the aim of achieving program objectives.

In many parts of the world, the negative repercussions following the lack of planning and coordination of infrastructure development is well noted [6]. Acknowledging this, the SIPs coordination institutional arrangement promoted an enhanced infrastructure coordination process, in contrast to earlier approaches which often resulted in unstructured and disintegrated approaches to project monitoring, oversight, evaluation, and implementation.

The TCTA SIP coordination function embodied the concepts of information gathering and sharing information on national infrastructure build programs at various platforms and meetings i.e., SIP Program Technical Committee (PTC) meetings, SIP Coordinators Forums (SCF), SIPs workshops, one-on-one sessions with the PICC, and other project and program partners. These engagements provided security of uniform, non-conflicting exchange of information, and assisted in reducing reporting duplication and inaccuracies during project and program progress reporting amongst stakeholders.

As a SIP-3 Coordinator, in performing its coordination and monitoring functions, the TCTA is guided by the Ministerial Directive, provisions of its Notice of Establishment of 2000, and the Public Finance Management Act (PFMA). Overall, TCTA was mandated to 


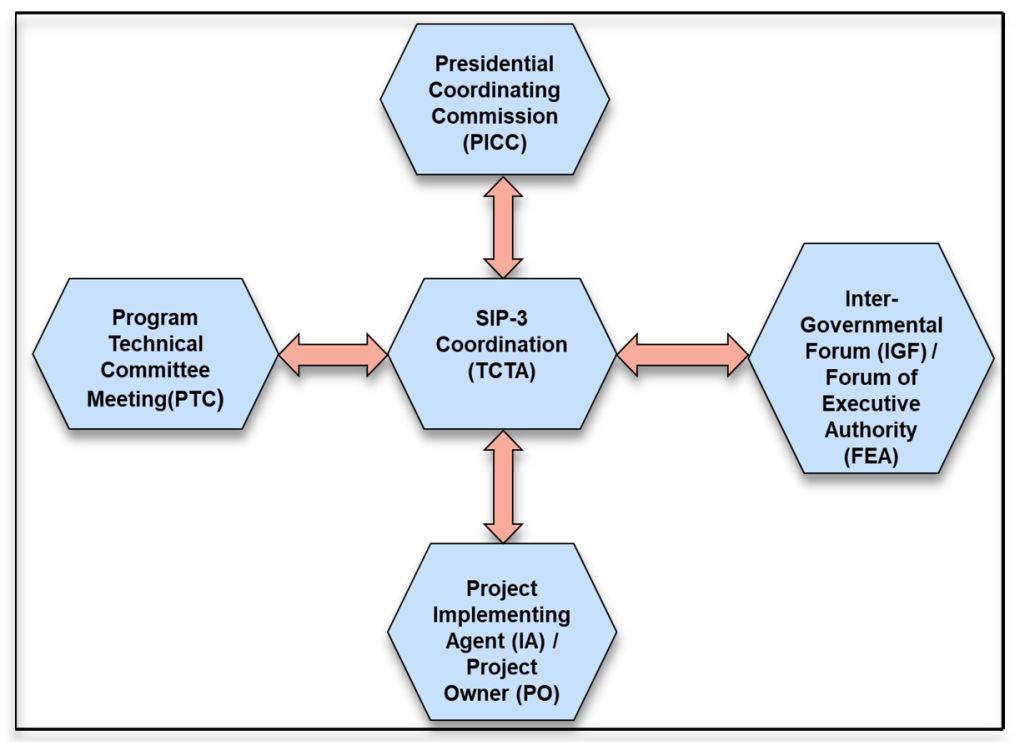

Figure 2: SIP-3 coordination institutional arrangements. (Source: SIP-3 Business Plan.)

establish and resource a Project Management Office (PMO). This PMO for most parts was authorised to: Coordinate deliverables and development plans; report on the construction jobs figures and localisation performance; assist the infrastructure implementation process in achieving the broader goals - including skills development, industrialisation, and localisation.

\section{SUSTAINING SOCIO-ECONOMIC GROWTH THROUGH INFRASTRUCTURE}

The "New Growth Path" framework identified structural problems in the economy and pointed to opportunities in specific sectors and markets or "jobs drivers" to reach its goal of five million new jobs by 2020 . The first jobs driver is infrastructure - laying the basis for higher growth, inclusivity, and job creation [7].

Infrastructure investment could be an extraordinarily useful tool for macroeconomic stabilisation [8]. With this in mind, providing infrastructure for communities and the economy is one of the leading ways South Africa can realise inclusive and jobs-rich growth. Quality, affordable infrastructure raises economic productivity, permits economic expansion, and allows marginalised households and communities to take advantage of new opportunities.

By convention, infrastructure is broadly divided into two categories: economic and social. Economic infrastructure conventionally covers traditional services like water, sanitation, roads, and electricity. Educational facilities, for example, are widely denned as social infrastructure, but play an important role in generating human capital, which is certainly also an economic function and carries important growth implications [9].

Addressing the Skills Gap - the gap between the skills of the current workforce and the skills businesses need to achieve their growth plans, is widening [10]. As far back as the former government, it was understood that there existed a massive shortage in the skilled workforce more especially amongst the youth in our society. 
The PICC highlighted the skills scarcity in SA as a significant challenge which needed urgent attention. As such, the SIPs programs was an opportunity to assume a key role in bringing about skills development within various sectors and disciplines.

For this to happen, a skills plan was required for SIPs. This task was best positioned to be headed by the Department of Higher Education and Training (DHET) and in collaboration with the Industrial Development Corporation (IDC).

SIP Coordinators would also play an integral part in the process of skills identification. The project owners of SIPs projects residing at State Owned Enterprises (SOEs), institutions and relevant authorities would also participate in identifying and proposing strategies to address the skills and training gaps and shortages that exist.

Promoting localisation - economic localisation refers to providing directed support for as many aspects of local production and consumption as possible [11].

Localisation is a key strategy known to drive local economic development linked to the progressing of local businesses and entrepreneurship. In addition to cultivating local businesses, localisation encourages condensed supply chains, thereby strengthening the local economy and simultaneously creating better community and business relationships.

The IDC, with its extensive experience and knowledge was tasked with progressing the SIPs localisation initiative through a Localisation Unit formed to assist entrepreneurs. SIP Coordinators were requested to provide support to the IDC in driving the localisation programme and integrating this idea with the delivery of SIPs infrastructure development to the benefit of local communities and businesses. It was envisaged that localisation would assume a key performance indicator to which the SIPs would be monitored against.

SIP-3 projects in terms of its program composition transcends sectoral boundaries, localisation would therefore benefit many business sectors. TCTA had given assurances in support of the localisation initiative in relation to the execution of the SIP-3 program.

\section{PROGRESS AND IMPACT OF THE SIP-3 PROGRAM}

Fig. 3 illustrates the SIP-3 project pipeline indicative of estimated capital costs. The total estimated value of the SIP-3 Program is in the region of R219 billion. Currently, R9.9 billion worth of projects are under construction.

As a way of highlighting key SIP-3 achievements, Fig. 3 outlines an overview of the program's progress from its inception to date by illustrating the measure of projects that were successfully completed - the red tabs indicate projects that have not progressed as anticipated and therefore reside within the initiation and planning phases of the project lifecycle. The blue tabs specify projects that have past the construction phase and are now complete and have been handed over to the respective clients for operations and maintenance.

Over the last 8 years during which time SIP-3 has been operational, admirable progress has been achieved through the completion of several projects (valued at about R18.9 billion), comprising: The Greater East London Strengthening, completed in 2015 - consists of an electricity transmission system for the Eastern Cape; the Nelson Mandela Legacy Bridge, completed in 2016 - creating better access to services and strengthening economic activity into Mvezo area and villages; the Kalagadi Manganese Sinter Plant and Mine located in Hotazel Northern Cape was commissioned in 2013 and 2016 respectively and are operational; the Mthatha Airport upgrade was completed in 2017 - improving access to the Eastern Cape business fraternity; the Ngqura Transhipment Hub completed in 2019 improving the export corridor via Ngqura in the Eastern Cape. 


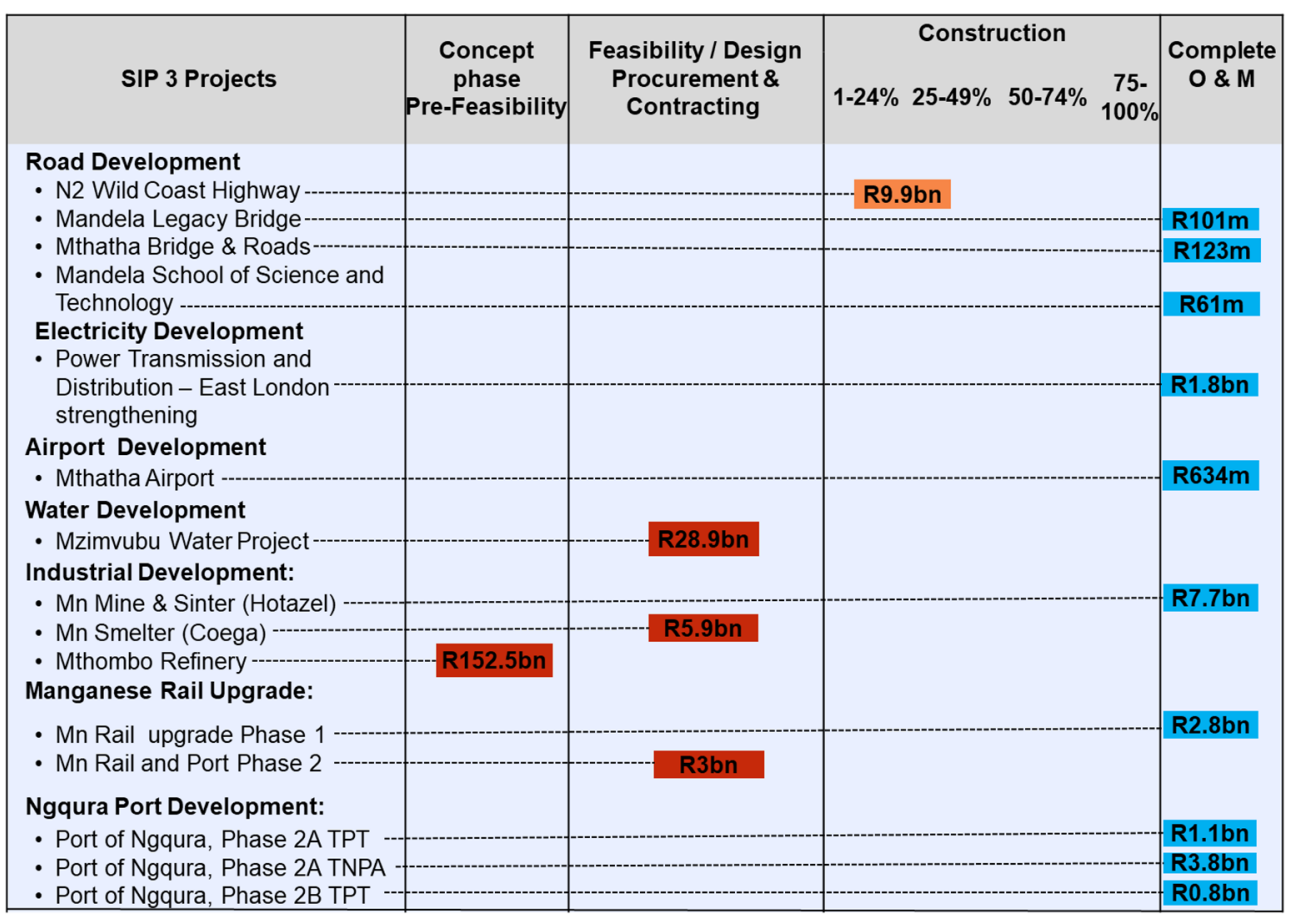

Figure 3: Status of SIP-3 projects, with estimated capital cost amounts. (Source: SIP-3 Progress Report.)

While noting the outstanding work above, there are some aspects of the program which have not progressed as planned. Therefore, it is important to highlight the challenges that confront SIP-3. These include the decrease in the number of active projects in the implementation phase. The following four of SIP-3's remaining five projects are among the large capital projects in the country: The Mthombo Refinery (estimated at R152.5 billion), the Mzimvubu Water Project (estimated at R28.9 billion), the Kalagadi Manganese Smelter (estimated at R5.9 billion) and the N2 Wild Coast Highway (estimated at R9.9 billion). These mega projects are considered catalytic for the economy of the corridor leading into the Eastern Cape province. However, they all face considerable challenges that hamper implementation. Part of the responsibilities of SIP-3 Coordination, is to unblock challenges that hinder project progress, SIP-3 had for years put in efforts to unlock these blockages, but regrettably have not yielded the desired outcome.

Given the complexity of the challenges, very few of the above-mentioned projects are likely to go into implementation soon. Having said that, the only exception is the N2 Wild Coast Highway project, which commendably has advanced into the construction phase, but continue to endure difficult challenges. Many of these challenges do fall outside the control of the implementing agent and cannot be easily unlocked, even at the level of political leadership.

Implementing the Kalagadi Manganese Smelter project has over the past several years been delayed because of volatile commodity prices. Due to challenges, three of the five remaining SIP-3 projects are stagnant, albeit the N2 Wild Coast Highway project is now 
progressing, SIP-3, in its current form, will depend mainly on the development of one project, being the Transnet Manganese Rail Upgrade, which thus far has experienced many lengthy delays. At present, execution of the Transnet project is temporarily halted due to an anticipated shift in strategy. This inevitably will delay the completion of the project even further having negative economic implications for the rail corridor and the Eastern Cape.

It is clear from the program status that an intervention is necessary to address stagnant projects and or to expand the project portfolio of SIP-3 with new catalytic projects.

\section{SIP-3 PROGRAM COORDINATION ACCOMPLISHMENTS}

The SIP-3 Coordination team has worked devotedly to identify and assist in resolving challenges or bottlenecks affecting project progress. The team have executed its responsibility in improving tracking, monitoring, and reporting of projects. SIP-3 Coordination encourage collaboration among key project partners through the creation of platforms for strategic engagement. These engagements stimulated information sharing amongst stakeholders and debating of issues that plague infrastructure development in South Africa. The coordination team has consistently prepared and submitted quarterly construction update and progress reports to the PICC, this included investigating and reporting of key project challenges. During its course of coordination efforts, SIP-3 had planned, convened, and facilitated two IGFs (also known as FEA as per the Act) where CEOs of state entities and political principles provided inputs into the program.

Further to the responsibilities and activities defined above, the SIP-3 Coordination team has been part of other critical interventions within the context of achieving the SIPs objectives. The following describe some of these interventions where SIP-3 Coordination was involved.

\subsection{Program Technical Committee (PTC)}

The SIP-3 PTC forum was established as a platform for program coordination on a technical level, where stakeholders can engage freely with the aim of resolving infrastructure implementation challenges and bottlenecks. But more specifically, the forum endeavoured to achieve the following objectives: Engage on SIP-3 construction update reports presented by project owners; provide an opportunity for project owners to gain insight into project related timeframes, inter-dependencies, potential risks that they may be faced with; enable provincial partners to engage in identifying opportunities for local economic development initiatives; create an opportunity for the SIP-3 Coordinator to identify challenges and solutions through engagement with key stakeholders.

\subsection{Integrating with other SIPs programs in resolving infrastructure and service delivery}

As part of SIPs initiative, government seeks to improve the quality of lives for its people, which includes people inhabiting the 23 least resourced districts as identified by the PICC. To achieve this goal, the PICC established SIP-6 which is dedicated to supporting coordination and integration of infrastructure delivery in these 23 districts.

The PICC had observed some inconsistencies between the reports provided by the various SIPs involved in these districts. This was due to limited coordination integration, and to improve coordination efficiency, it was resolved that a working group dedicated to supporting the 23 districts be established. Also, noting that most of the 23 affected districts were in the Eastern Cape region made sense for SIP-3's involvement, providing strategic support to this initiative. SIP-3 Coordination has also supported by tracking progress and 
unblocking bottlenecks affecting delivery of infrastructure and the following important services to communities: Water and sanitation; electrification; roads; health care facilities; schools; digital migration; broadband and human settlements.

\subsection{Supporting SIPs skills development}

The Eastern Cape province is where most of the SIP-3 projects reside, is largely rural and is home to a substantial portion of South Africa's unemployed population which contribute to its growing levels of poverty. The SIPs Skills strategy envisioned the creation of job opportunities beneficial in improving the livelihoods and quality of life of the communities within this province. SIP-3 Coordination committed to working closely with and support those championing the SIPs skills initiative (IDC and DHET). SIP-3 engaged often with the DHET and assisted by providing support in the development of the SIP Skills Plan.

\subsection{Supporting localisation}

As part of the assistance provided to the IDC's Localisation Unit, the SIP-3 Coordination team identified localisation opportunities that exist within the program. In this regard, SIP-3 earmarked key opportunities relative to SIP-3 projects, and highlighted enablers that would elevate localisation and the economy in communities and the region. Through these opportunities, SIP-3 embraced the localisation vision for businesses to support the SIP infrastructure build program through spin-offs in establishment of local small to medium businesses and concurrently establish job opportunities. Further to this, SIP-3 also highlighted opportunities for promoting localisation within the labour sector where most of the semi-skilled and unskilled labour recruited for SIPs projects could be sourced from local communities. This labour localisation approach was brought to the fore to significantly address the skills shortage.

\section{SIP-3 PROGRAM AND SIP COORDINATION CHALLENGES}

Over the years of SIPs implementation there have been many challenges confronted by Coordinators that impact SIPs programs. Most of these coordinating and program challenges are shared across most SIPs. The following are some key challenges that is specific to SIP3, but are not uncommon to other SIPs programs:

Diminishing Number of Active SIP-3 projects - significant projects in SIP-3, in terms of value, have not advanced as anticipated. The current portfolio of active projects has diminished and in need of augmentation to maintain the momentum in catalysing the economic development of the Eastern Cape region. SIP-3 Coordination started an initiative, in collaboration with the PICC, to enhance the program by incorporating new strategic and catalytic projects. SIP-3 had engaged with the Eastern Cape Socio-Economic Consultative Council (ECSECC) and the Eastern Cape Department of Economic Development, Environmental Affairs and Tourism (DEDEA) including other key Stakeholders during the Eastern Cape Economic Cluster meeting held in October 2016, to request guidance with the process of selecting new projects to augment SIP-3. Further to the above, SIP-3 Coordination and the PICC have also engaged with the Eastern Cape Office of the Premier in September 2017 to gain an improved perspective toward progressing the SIP-3 enhancement initiative within the province. The meeting was a productive one, but due to certain political challenges, resulted in the enhancement initiative not progressing as hoped. In fact, it came to a standstill in the latter part of 2017. 
Several projects within SIP-3 have failed to gain traction due to funding challenges. Broadly speaking, funding constraints on SIPs were observed to be systemic and cutting across all the strategic programmes. Using SIP-3 to illustrate the challenge, a greater portion ( $87 \%$ of estimated R219 billion) of the program value has failed to progress into the construction phase. As a result, the planned economic catalysis and social development benefits planned for the Eastern Cape are being held back.

With a weakened economy and dwindling fiscus which precedes the resultant effects of regulations associated to COVID-19 lockdowns, South Africa is in a difficult position with respect to its sovereign credit rating and its ability to raise appropriate funding for infrastructure. Yet, there remains a huge degree of optimism by Government through an introduced economic recovery plan announced in October 2020 which prioritises infrastructure spending via an Infrastructure Fund (IF) managed by the Development Bank of South Africa (DBSA) [12]. The IF is seen as a key element of the economic recovery plan and aims to diversify government funding sources available for infrastructure by combining capital from the public and private sectors, development finance institutions and multilateral development banks [13]. Government funding plans are admirable but considering the urgency of infrastructure demands faced by SA, a detailed funding strategy is essential to demonstrate the availability of funding and allocations to prioritised strategic infrastructure projects [14].

Funding for SIP Coordinators - when state entities were directed by various Ministries to be SIP Coordinators, funding did not accompany these directives, making it difficult to appropriately execute responsibilities of the coordination function. Due to the lack of dedicated funding, the TCTA SIP team have experienced challenges in validating the cost associated with the coordination of SIP-3, by the same token, SIP-18 being the other SIP program which the TCTA has been directed to coordinate, also share the same funding issues. Considering SA's protracted poor economic climate, some state entities responsible for SIP Coordination, including the TCTA, have had to carry out SIP coordination work with very limited resources.

Localisation and Job Creation - as with SIP-3, most SIP Coordinators functioned with limited resources while aiding the IDC Localisation Unit in driving the localisation, industrialisation, and Job creation initiatives. These initiatives deserve concerted effort and is not a quick process, necessitating continued research in identifying opportunities and new suppliers and allowing further time for entrepreneurial development and growth. In $2012 \mathrm{a}$ Business Plan for SIP-3 that TCTA submitted to the PICC contained localisation opportunities and associated benefits within the various sectors of the SIP-3 program. The SIP-3 Business Plan was approved by the PICC Secretariat. Since then, there have been many engagements with the Localisation Unit, though there hasn't been significant progress.

South Africa still grapples with increasing levels of unemployment [15]. Overall, the will and required framework to ensure localisation is in place, yet a key challenge extends to government and SOEs that still lack implementation capacity. Just one example of this lies in the limited capacity of procurement officers to select local suppliers, which is critical to ensure effective implementation [16].

\section{STAKEHOLDER INSIGHTS ON SIPS AND SIP-3}

Insights from SIP-3 stakeholders are highlighted below, reflecting on their experiences, perceptions and views of the successes and challenges encountered during coordination of the SIP-3 program. These insights and views also develop a deeper understanding of the program's performance. The stakeholders who engaged with the SIP-3 Coordination team in discussions included: Managers and SIPs leads from the PICC; SIP-3 Project Owners 
(Transnet, Eskom, TCTA and SANRAL) and Eastern Cape Provincial Partners (ECSECC and DEDEAT).

A common view expressed by Project Owners (POs) were of infrastructure having not realised the economic benefits and jobs creation post construction. The SIP-3 Mthatha Airport upgrade was used as an example of completed infrastructure having great economic potential had it been appropriately and timeously planned for. As emphasised by POs, prioritised projects should be an ideal candidate for appropriate financing and should be implementation ready to secure economic benefit soonest. POs stated that projects under SIPs should not form part of a "wish list" - SIP projects should be weighed upon its ability to drive catalytic economic growth. As part of the SIP-3 review process, POs debated that the economic impact of SIPs be measured. However, this argument concluded by the understanding that it would be difficult to measure at this stage and would need a more comprehensive study into the business and operational plans of every project and all catalytic benefits that were derived therefrom. POs impressed upon the idea of SIP Coordinators involvement in the project selection process. It was of the view that the constitution of the current SIPs programs (SIPs 1 to 18) were not appropriately selected due to a rushed selection process. Requests were made for a better synchronised process in infrastructure roll-out and for SIP Coordinators to play a more active role in future SIPs selection.

The PICC in general had commended SIP-3 Coordination in progressing the SIP-3 projects, The PICC pointed out that there were many positives resulting from SIP-3's coordination efforts. Nonetheless, the PICC had also indicated that there is still room for improvement. The key issue in the SIP-3 program is funding - within the context of a weakened economy, the funding challenge persists and is one that is not easily resolved, even by political principals, as such, this challenge does necessitate concerted effort to overcome.

The following matters were also highlighted by the PICC as areas were improvement in SIP-3, including other SIPs can be fostered, by all SIP stakeholders:

- Project selection should have sound planning and full feasibility studies;

- Efficacy of the SIP process in achieving its objective of social and economic development;

- An empowered review process is needed to appraise projects against SIP objectives prior to being uploaded as a SIP;

- Enforce "obligations" on POs having projects in SIPs programs - there are certain POs that do not regularly and effectively report on project progress and challenges;

- Regularly review and update projects in the SIPs programs - prioritised pipeline of projects must be implementation ready and should not remain stagnant over years;

- Improve SIP-3's efforts in enabling localisation, skills development and job creation these initiatives are key to economic prosperity.

Provincial partners related the need for job creation and skills development which were not realised as envisioned. Hence, provincial partners questioned if SIPs were in fact strategic and adequately integrated within infrastructure development plans for the province. A concern over the political fraternity was highlighted with respect to projects that were announced as being ready for construction, but regrettably were not delivered as promised these unfulfilled declarations severely impact on beneficiaries needs. The following proposals were also highlighted by SIP-3 provincial partners to improve SIPs operations:

- Entrench better integration at project and program level across SIPs;

- SIP Coordinators and supporting structures must be given more authority, being better empowered in driving the SIPs agenda; 
- Secrecy and "silos" from SIPs program coordination and reporting should be detached project information sharing should be further encouraged, even at the political level;

- SIP-3 Coordination should be more involved in project implementation decision making - i.e., project launch announcements by politicians, funding, strategy review and stakeholder engagement.

\section{CONCLUSION AND RECOMMENDATIONS}

SIP-3 stakeholders had provided valuable insights into why the SIP-3 program can be considered effective or alternatively not as effective as it was initially imagined. Although many stakeholders had spoken proudly of the benefits experienced with SIP-3, generally the principal view by most was that the SIPs Coordinators and the PICC be further empowered.

While embracing all views from stakeholders, the benefits associated with a project being part of SIP-3 should be emphasised. Broadly speaking, SIPs programs does promote integrated project planning, design, and execution, including a focus on completed projects, are well operated, managed and maintained, particularly as SA battles with a vast backlog of infrastructure that is in disrepair and at risk of collapse [17].

In addition, projects selected for SIPs programs are not selected in isolation but are reviewed on their relationship with broader regional or national development programs. The SIPs approach promotes systems and integrated thinking and planning. SIP-3 collaboratively functions with other Coordinators and stakeholders to promote strategic unblocking of key challenges that projects generally encounter.

While SIPs status does not automatically qualify a project for funding, it does give it a higher level of preference should funding be available. However, supporting SIP-3 and other SIPs with access to available funding is fundamental in successfully implementing an infrastructure-led economic growth. Globally, especially in countries where infrastructure development programs are meeting its economic development goals have been incorporating widely researched and detailed funding strategies - Public-Private Partnerships (PPP) funding approach is moreover proving successful in public infrastructure development. Given governments' funding constraints, the PPP - has emerged as a new way to deliver and govern infrastructure assets [18]. Noting this perspective, SA does require more effort in developing and promoting PPPs that support infrastructure development.

PICC need to assist SIP-3 and other Coordinators in ensuring that the FEA assemble regularly, including establishment of SIPs Steering Committees to provide strategic guidance and support as stipulated in the Infrastructure Development Act. These critical structures have not been effectively instituted and if properly functioning would help accelerate decision-making, unblocking of challenges and fast-tracking program progress in achieving SIPs socio-economic objects.

As acknowledged by SIP-3, the value of coordinating national infrastructure also lies in undoing "silos" that exist not only at a project or institutional level but also at a departmental and ministerial level. SIPs encourages collaborations and new ways of shared thinking across multifaceted issues that affect society and its relationship with infrastructure, and it improves access to quality infrastructure and efficient services by communities.

Furthermore, it must be said, that with any initiative or intervention, especially one which is a pillar of inordinate significance to a nation's economic reconstruction and recovery [19], must be strengthened by refined policies, regulations, and will. Policies must be wholeheartedly supported, and aimed at a sustained, robust, and impactful infrastructure coordination structure. 


\section{REFERENCES}

[1] National Planning Commission (NPC), National Development Plan (NDP) 2030.

[2] Presidential Infrastructure Coordinating Commission (PICC), National Infrastructure Plan (NIP), 2012.

[3] United Nations, 2030 Agenda for Sustainable Development. https://sustainabledevelopment.un.org. Accessed on: 11 Aug. 2021.

[4] Parliamentary Monitoring Group, Infrastructure Development Bill [B49-2013]: Minister's Briefing, Economic Development, Nov. 2013.

[5] Organisation for Economic Co-operation and Development (OECD), 2006 Annual Report on Sustainable Development Work in the OECD, 2006. www.oecd.org. Accessed on: 12 Aug. 2021.

[6] Economic and Social Commission for Asia and the Pacific (ESCAP), Infrastructure Development as Key to Economic Growth and Regional Economic Cooperation, 1994. www.unescap.org. Accessed on: 13 Aug. 2021.

[7] South African Government, The New Growth Path Framework, Nov. 2010.

[8] Bivens, J., The Potential Macroeconomic Benefits from Increasing Infrastructure Investment, Economic Policy Institute. www.epi.org. Accessed on: 13 Aug. 2021.

[9] Fedderke, J. \& and Garlicky, R., Infrastructure Development and Economic Growth in South Africa: A Review of the Accumulated Evidence, May 26, 2008.

[10] PricewaterhouseCoopers, Skills gap is hampering businesses' recruitment efforts. www.pwc.co.za. Accessed on: 20 Jun. 2021.

[11] Frankova and Johanisova, Economic Localization Revisited, 2011.

[12] Bulbulia, T., Government commits to improving infrastructure spend, Engineering News. www.engineering news.co.za. Accessed on: 11 Jun. 2021.

[13] National Treasury Republic of South Africa, Budget Review, 2021, www.treasury.gov.za, www.engineering news.co.za. Accessed on: 12 Jun. 2021.

[14] Public Works and Infrastructure, SA's Infrastructure Investment Plan post COVID19 with Minister. pmg.org.za. Accessed on: 15 Jun. 2021.

[15] Statistics South Africa, Budget Review, 2021. www.statssa.gov.za. Accessed on: 15 Jun. 2021.

[16] Development Bank South Africa (DBSA), Infrastructure Dialogues, Localisation: Driving Industrialisation through the National Infrastructure Plan, Nov. 2014.

[17] South African Institute of Civil Engineers (SAICE), Infrastructure Report Card for South Africa, 2017.

[18] Levitt, E., Richard, W. \& Garvin, J., Public-Private Partnerships for Infrastructure Development, 2019.

[19] South African Government, The South African Economic Reconstruction and Recovery Plan. www.gov.za. Accessed on: 20 Jul. 2021. 